\title{
The Importance of Communication among the Members of the Nursing Team
}

\author{
Lucas Warmling1, Patricia Alves de Souza² \\ ${ }^{1}$ Hospital Caridade Maternidade São José, Urubici, Brazil \\ ${ }^{2}$ Universidade do Planalto Catarinense (UNIPLAC), Lages, Brazil \\ Email: lu_warmling@hotmail.com, passpb@gmail.com
}

How to cite this paper: Warmling, L., \& de Souza, P. A. (2018). The Importance of Communication among the Members of the Nursing Team. Creative Education, 9, 993-999.

https://doi.org/10.4236/ce.2018.96073

Received: March 8, 2018

Accepted: May 28, 2018

Published: May 31, 2018

Copyright () 2018 by authors and Scientific Research Publishing Inc. This work is licensed under the Creative Commons Attribution International License (CC BY 4.0).

http://creativecommons.org/licenses/by/4.0/

\begin{abstract}
In 2013, the Brazilian Ministry of Health instituted the National Patient Safety Program ("PNSP"). One of the priorities of the Program is to propose and validate protocols, guides and manuals aimed at patient safety in different areas, one of which is communication concerning the health services environment. The hospital performs actions in tertiary care and the interpersonal communication of the nursing team demands a lot of attention and care, since it is a fundamental instrument in order to help the recovery of the patient. With a basis in this, the present work aims to identify the perceptions regarding the forms of communication of the members of the nursing team, the elements that interfere in this communication and to discuss the importance of the communication process among the nursing teams. This is a qualitative and descriptive research carried out from a questionnaire applied to nursing professionals of a small hospital in the Brazilian state of Santa Catarina. There is a lack of communication and we noticed that the interaction among the members of the nursing team and the participation of the health institution must be improved in order to achieve a better teamwork. This improvement can be applied not only during the work process, but also through lectures, meetings and fellowship encounters. The communication occurs through an active participation of two or more individuals in the relevant process and such relationship may facilitate the practice of humanization. Communication subsidizes interpersonal relationships that, in turn, interact with nursing art, which is the process of science and care.
\end{abstract}

\section{Keywords}

Communication, Nursing

\section{Introduction}

Patient safety in health services is part of the political agenda of the Member 
States of the World Health Organization (WHO), and during the $57^{\text {th }}$ World Health Assembly, the attention to the subject "Patient Safety" was recommended to countries. The priorities of the implementation of the Patient Safety Core in Brazil are the proposal and the validation of protocols, guides and manuals for achieving safety in different areas, one of which is communication in the health services environment (Brasil, 2013).

Communication is vital for the construction of a community and its organization, in order to structure the relations among society and the individuals (Spagnuolo \& Pereira, 2007). Communicating is the process of transmitting messages from person to person, through speech, writing, images and sounds in order to generate knowledge (Kurcgant et al., 1991).

Communication is essential for quite good interpersonal skills and best quality of service.

The communicative process is essential in a nursing team in order to guarantee the excellence of the work, which consequently provides conformations that allow the understanding of the functions and the good relationship among the professionals and the patients/clients. In order to improve or perform nursing care, it is very important to pay attention in the back and forth conversation, which brings people together and begins a closer contact and integration relationship, as well as allows an exchange of experiences and experiences.

The process of humanization can be carried out in an effective and transformative way through a communication approaching in order to unveil and respect the professional being, thus allowing a continuous understanding of the reality of the patient and the worker (Backes, Lunardi, \& Lunardi, 2006).

Communication among the nursing teams is often unstable by daily life and poorly resolved interpersonal relationships. People are "robots" and perform their functions in an automatically way, forgetting that the work object is the patient. In order to achieve the patient's welfare, it is necessary that teamwork is combined with good interpersonal skills and worthy communication.

The act of communicating facilitates and approaches personal interactions, causing a more pleasant and productive communication. The organization becomes a large system of information processing and extends the possibility of a better use of the individual and sectoral capacities of the institution, due to the possibility of information exchanges (Motta, 2002).

Communication is vital to the relationship among individuals and organizations that influence each other and turns facts in information (Takahashi \& Pereira, 1991).

Freire (1983) teaches that communication is at the heart of the thought process: "Every act of thinking requires a subject who thinks about an object of the second and the communication between the two is given through linguistic signs. In this sense, the human world isa world of communication" (p. 25).

Communication is a feature of the human beings and we depend on it in order to survive and perpetuate the species, culture, science and all the affairs that 
has been achieved since the primitive age. Communication is part of each person's history, a complex process that encompasses comprehension, emission and reception of messages that have immediate effects on the behavior of people involved in the interaction environment in the medium and long term (Braga \& Silva, 2007).

An efficient communication relationship between the members of the nursing team contributes to the fact that the interrelationships established in the work delimit better if patient care will be humanized or not. In order to achieve the process of humanization is necessary that each professional must be respected in his/her individuality (Broca \& Ferreira, 2012).

Communication is necessary in the act of developing the nursing profession, but even though it is essential in professional practice, communication, itis not always done, because several negative aspects interfere in the communicative action of the personnel involved (Santos \& Silva, 2006).

The use of communication is essential among members of the nursing team, as it aims to strengthen the interpersonal relationships of these professionals and provides a better capacity in the performance of their duties.

This study aims to identify the way in which interpersonal communication occurs between the nursing team of a small hospital in the Brazilian state of Santa Catarina.

\section{Methodology}

This is a qualitative and descriptive research aimed at the nursing care provided and the perception of the nursing team about the communication. This research was performed in a small hospital in the Brazilian state of Santa Catarina, which provides $95 \%$ of public service through the philanthropic Single Health System. All nine employees of the nursing team were invited to participate in the study, six of whom agreed to participate and are identified by the letter E (employee) and by a subsequent number that will allow the participants to remain anonymous. A questionnaire with 06 (six) open questions was applied.

The questionnaires were analyzed according to content analysis according to Bardin (2011), and the following categories were found: nursing care failure due to communication, importance of communication in nursing, negative feelings among the team.

This research was approved by UNIPLAC'S Ethics and Research Committee under the number CAAE 51859215.2.0000.5368.

\section{Results and Discussion}

The nursing team profile was described. Regarding the age of the employees, it was observed that one (1) employee was in the age range of 20 to 25 years (16.5\%); one (1) employee was in the age range of 26 to 30 years (16.5\%); three (3) employees were in the age range of between 31 and 35 years (50.5\%); and one (1) employee was in the age range of 41 to 45 years (16.5\%). Regarding the 
gender composition of the team, four (4) employees answered that they are female (66\%); one (1) male (17\%) and one (1) transgender (17\%). Regarding the length of professional experience, from a total of six (6) employees one (1) has 1 to 5 years of professional experience (17\%); four (4) employees have 6 to 10 years of experience (66\%); and one (1) has 11 to 15 years of experience (17\%).

In a study carried out by Freitas \& Oguisso (2007), the nursing team studied consisted of: $64 \%$ of females, $34 \%$ of males and the predominant age group was between 30 and 39 years old (46.2\%), followed by the age group of $40-49$ years $(24.2 \%)$ and 20 - 29 years (19.9\%). Regarding the length of professional experience, the study noted $38.7 \%$ under three (3) months, followed by $26.3 \%$ over seventy-two (72) months. As the present research, the statistics listed by Freitas show that most people engaged in the field of nursing is female, aged between 30 and 40 years and they have considerable time experience in the field (Freitas \& Oguisso, 2007).

Regarding the category "nursing care failure due to communication":

F6: I think it is precarious, with many failures, because most of the times the routine events and setbacks occurring at work are not reported, diverting to parallel conversations.

F1: Reasonable, they (nursing team) deal with parallel conversations and do not prioritize nursing care; in relation to the care, they do not give importance, they do not know why they must be careful and simply do things, not getting rich of guidelines and leaving important data during the passage of duty [...] because the lack of medical records, we notice the non-application of systematization and also a care that was important and was not transmitted nor recorded in the medical record, another point of failure.

F5: In my opinion there is a lack of communication among colleagues, important reports of the patient's passage are often not passed on to everyone on the team... the bad points of poor communication are that you omit patient reactions and complaints.

From the reports narrated above, it was possible to observe that there are difficulties in communication between the members of the nursing team, which causes losses to patient care.

In a hospital area research the results obtained were: lack of information, objectivity and clarity that allows the effectiveness of a quality service. A change of communication for an effective service is of fundamental importance (Manzo, Brito, \& Alves, 2013).

In relation to the category "importance of communication in nursing", the reports are the following:

F2: I find it necessary, because it facilitates the work before the patients, the doctor and even my colleagues.

F3: Good communication, because communication is fundamental to good fellowship. 
F5: The strengths of good communication reveal a power for helping the team in order to improve care and patient well-being.

F1: It is important for the continued assistance and comprehensive care, both necessary for s nursing.

Good communication among members of the nursing team is of fundamental importance for closer ties of companionship to provide better patient care.

For a safe and humane treatment of patients in a hospital, it is essential that teams of professionals work in a harmonized way, emphasizing listening, dialogue and empathy (Carvalho et al., 2015).

The third category called "negative feelings among the team", generated the following responses:

F1: this problem is unfortunately present, which makes the diagnosis difficult, there is a lack of systematization in nursing; poor reports or no shift on duty, communication about the patient is precarious and there are parallel conversations.

F2: It creates stress, because generates doubts on certain issues; sometimes we need to call colleagues at inopportune times and out of working hours moments.

F4: Misinformation, disturbance of colleagues outside working hours, withdrawal of untruthful communications before knowing the truth of the facts.

F 6: Failure in care, which puts patients' lives at risk.

It was observed that communication problems cause distance among the members and generate negative feelings that interfere in the relationship between the members of the nursing team.

The hospital environment generates fears, anguish and afflictions. Proper communication between the team allows reduction of these feelings that often can contribute to complications and losses to the health of the patient (Fassarella, Cruz, \& Gibbs, 2009).

In order to achieve communication, one of the great challenges is the adoption of dialogue measures and practices that prioritize the conversation and the exchange of experiences, giving importance and sharing the knowledge of the people involved (Spagnuolo \& Pereira, 2007).

When observing the speech of the nursing team, the needs of each one were evidenced, as well as their limitations and problems related to the nursing routine. The small size of the hospital and the reduced staff are factors that could facilitate good communication, but another reality has been discovered.

\section{Final Considerations}

The present research pointed out failures in the communication that, in order to be repaired, the form of interaction among the team members should be improved. 
The result of good communication will only be effective when the team begins to work in tune, because communication occurs not only verbally, but is also manifested by attitudes, gestures, and facial expressions. With this, it is important that one person put her/himself in the place of the other and thus anticipate her/his thoughts and beliefs. This attitude will facilitate the understanding, reduce conflict and hence the interpretations of all forms of communication will have a satisfactory outcome with respect to interpersonal relationships and cares with the patient.

There is communication only if two or more individuals actively participate in the process and this relationship may facilitate the practice of humanization. Communication subsidizes interpersonal relationships, which, in turn, interact with the art of nursing, a process of science and care.

It is worth mentioning that a partnership between the team and the hospital institution in order to promote greater training will encourage good relationships through clear communication. A systematization of the service can improve the way of thinking and acting, thus favoring communication between the teams.

Thus, the research results identified the way in which interpersonal communication occurs between the nursing teams. Although there are communication failures, there is also an optimization that good communication is the point of balance for a quality care to the patient/client.

\section{References}

Backes, D. S., Lunardi, V. L., \& Lunardi, W. F. (2006). A humanização hospitalar como expressão de ética. Revista Latino Americana de Enfermagem, 14, 132-135. https://doi.org/10.1590/S0104-11692006000100018

Bardin, L. (2011). Análise de conteúdo (p. 229). Lisboa: Edições 70, LDA.

Braga, E. M., \& Silva, M. J. P. (2007). Comunicação competente-visão de enfermeiros especialistas em comunicação. Acta Paulista Enfermagem, out-dez, 20, 410-414. https://doi.org/10.1590/S0103-21002007000400004

Brasil (2013). Portarial $n^{\circ}$ 529, de $1^{\circ}$ de abril de 2013. Brasília: Institui o Programa Nacional de Segurança do Paciente (PNSP).

Broca, P. V., \& Ferreira, M. A. (2012). Equipe de enfermagem e comunicação: contribuições para o cuidado de enfermagem. Revista Brasileira de Enfermagem, 65, 97-103. https://doi.org/10.1590/S0034-71672012000100014

Carvalho, D. O., Santos, N. N. R. C., Silva, A. R. V., \& Carvalho, G. C. N. (2015). Percepção do profissional de enfermagem acerca do cuidado humanizado no ambiente hospitalar. Revista interdisciplinar, 8, 61-74.

Fassarella, C. S., Cruz, D. S. M., \& Gibbs, G. (2009). Análise de dados qualitativos. Porto Alegre, Artmed.

Freire, P. (1983) Extensão ou comunicação? Rio de Janeiro: Paz e Terra.

Freitas, G. F., \& Oguisso, T. (2007). Perfil de profissional de enfermagem e ocorrências éticas. Acta Paulista de Enfermagem, 20, 489-494. https://doi.org/10.1590/S0103-21002007000400017

Kurcgant, P., Cunha, K. C., Massarollo, M. C. B., Ciampone, M. H. T., Silva, V. E. F., 
Castilho, V., et al. (1991). Administração em Enfermagem. São Paulo: EPV.

Manzo, B. F., Brito, M. J. M., \& Alves, M. (2013). Influencia da comunicação no processo de acreditação hospitalar. Revista brasileira de enfermagem, 66, 46-51.

Motta, P. R. (2002). Gestão contemporânea: a ciência e a arte de ser dirigente (13a ed.). Rio de Janeiro: Record. https://doi.org/10.1590/S0034-71672013000100007

Santos, K. M. A. B., \& Silva, M. J. P. (2006). Percepção dos profissionais de saúde sobre a comunicação com os familiares de pacientes em UTIs. Revista Brasileira de Enfermagem, 59, 61-66. https://doi.org/10.1590/S0034-71672006000100012

Spagnuolo, R. S., \& Pereira, M. L. T. (2007). Praticas de saúde em enfermagem e comunicação: Um estudo da revisão da literatura. Ciência \& saúde coletiva, 12, 1603-1610. https://doi.org/10.1590/S1413-81232007000600021

Takahashi, R. T., \& Pereira, L. L. (1991). Lideranças e comunicação. Revista da Escola de Enfermagem da USP, 25, 123-135. https://doi.org/10.1590/0080-6234199102500200123 